\title{
Research of Mechanical Properties of Random Disordered CuNi Alloys
}

\author{
S. K. Parida, M. Mohanta, M. A. Sahoo, R. Meher, V.R.R. Medicherla
}

\begin{abstract}
Preparation technique and structural analysis of random CuNi disordered alloys have been discussed. The arcmelting method is used to prepare different compositions of substitutional random disordered Cu1-x Nix (0.1, 0.3, 0.5, 0.7, 0.9) alloys. The stoichiometric amounts of highly purity constituents copper and nickel metals $5 \mathrm{~N}$ (99.999\%) have been melted under argon atmosphere in vacuum chamber of 10-3 torr. The substitutional random disordered alloys free from carbon and oxygen traces are confirmed from XPS data. A lattice strain is produced in CuNi alloys as the environment of Ni atoms change from sites to sites. Lattice parameters, unit cell volume, structure and inter-planar spacing were calculated from XRD analysis. The average crystallite size of different compositions of random disordered CuNi alloys is calibrated by using Scherer's method and Williamson-Hall (W-H) method. The roles of crystallite size and lattice strain on the XRD peak broadening of the random disordered $\mathrm{CuNi}$ alloys were analyzed. The strain increases with increase in concentration of $\mathrm{Ni}$ and exhibits a maximum of 0.00247 at $50 \% \mathrm{Ni}$ concentration. The CuNi alloys find very wide applications in oil refining and long corrosion free life.
\end{abstract}

Index Terms: arc-melting, binary alloys, crystallite size, lattice parameter, \& $\mathrm{W}-\mathrm{H}$ analysis.

\section{INTRODUCTION}

Formation of substitutionally random disordered $\mathrm{A}_{1-\mathrm{x}} \mathrm{B}_{\mathrm{x}}$ alloys is one of the advance steps in ceramics [1], semiconductor [2] and metallurgy [3] to facilitate new findings in science and technologies. In the alloys, atom B may be localized randomly or in very unique way of periodic distribution. The effect of randomness or periodicity in substitutionally random alloys may be the cause of the presence of various types of carriers [4], bonds [5] and excitons [6-7]. The composition and microstructure are general used to predict mechanical behaviors of a material by scientists and engineers. Complete understanding of mechanical behaviors of materials remains mystery for long time and attracts many researchers. Generally, an alloy is formed by intermixing of two or more elements. The complete burning of two solid metals solution form single phase alloys while two or more phases may found from incomplete solid solutions which depends on the thermal treatment.

\footnotetext{
Revised Manuscript Received on September 14, 2019.

S. K. Parida, Department of Physics, ITER, Siksha 'O' Anusandhan (deemed to be University), Bhubaneswar-751030, Odisha, India.

M. Mohanta, Department of Physics, ITER, Siksha 'O' Anusandhan (deemed to be University), Bhubaneswar-751030, Odisha, India.

M. A. Sahoo, Department of Physics, ITER, Siksha 'O' Anusandhan (deemed to be University), Bhubaneswar-751030, Odisha, India.

R. Meher, Department of Medical Physics, Acharya Harihar Regional Cancer Centre, Cuttack, Odisha, India.

V.R.R. Medicherla, Department of Physics, ITER, Siksha 'O' Anusandhan (deemed to be University), Bhubaneswar-751030, Odisha, India.
}

The thermal properties of individual constituent elements are different from the alloys [8-13]. Any composition of $\mathrm{CuNi}$ alloys can be formed because of strong miscible character of $\mathrm{Cu}$ and $\mathrm{Ni}$ atoms and thus formed random disordered alloys. Every random disordered alloys show chemical shift because introduction of disorder in alloys forced to change the inhabitant framework from atomic sites to atomic sites which manifests core level shift and core disordered broadening [14-23]. The microscopic properties of substitutionally random disordered alloys display from perfectly ordered alloys. Disorder performs a crucial role in condensed matter because of many challenging and interesting problems have been directly or indirectly connected to disorder. Sometime we observe weak disorder in alloys which may be result of an anxiety of the perfect crystalline ordered alloys. Defects, dislocations and vacancies are the examples of this category in material science. But in case of strong disorder found in random disordered alloys can be indentify from a large deviation from crystalline order. There have been extensive theoretical and experimental studies to determine of the effective lattice parameter in more complex alloy systems [24]. Random disordered $\mathrm{CuNi}$ alloys have been subject of substantial study due to their future applications in different areas like electronic industry, fire extinguisher, resistance to biofouling, desalination, resistant to corrosion, acid resistant, commentators, remelted and reused properties and catalysis etc [25-27]. Though the $\mathrm{CuNi}$ alloys were subjected to investigations for several decades, the role played by disorder on mechanical properties such as lattice strain and elastic moduli is not well understood.

In this paper, we discuss the method of preparation of substitutionally random $\mathrm{Cu}_{1-\mathrm{x}} \mathrm{Ni}_{\mathrm{x}}(0.1,0.3,0.5,0.7,0.9)$ alloys. The XRD analysis is done to calculate lattice parameters, unit cell volume. Due to arc-melting of binary solid solution of two metals, $\mathrm{Ni}$ atoms interact in the vicinity $\mathrm{Cu}$ producing lattice strain is calculated using the Williamson-Hall relation.

\section{EXPERIMENTS}

The arc-melting technique is being used to prepare the substitutionallyrandom $\mathrm{Cu}_{1-\mathrm{x}} \mathrm{Ni}_{\mathrm{x}}(\mathrm{x}=0.1,0.3,0.5,0.7,0.9)$ disordered alloys. The stoichiometric amounts of high purity (99.999\%) $\mathrm{Cu}$ and Ni metals are put in the high temperature resistant copper hearth under argon atmosphere inside the arc furnace. The environment of the arc furnace is maintained the vacuum pressure around $10^{-3}$ Torr and slowly the argon gases were injected inside the chamber to maintain 
the said pressure. To liberate the presence of oxygen traces from the vacuum chamber, a small titanium ball was melted near the copper hearth. The special character of the titanium is to form various oxide compounds during its melting period and help to release the oxygen from the chamber. It is convenient to put the metal having high melting point on the top over the metal having low melting point inside the copper hearth sothat top metal will receive more heat and transfer to the bottom for better mixing. This method is also help to maintain the stoichiometric ratio of the inter-mixing elements by giving differential heating simultaneously. It is advisable to repeat the melting several times to crush the chunk that comes in each time. Some time, though sufficient care has been taken for removal of the oxygen trace from the chamber, it seems difficult to say the samples were completely free from oxygen impurities. Some residual oxygen impurities were still present in the samples and stay preferably in the inter-grain regions. For the removal of such oxygen traces, one has to anneal the prepared samples below the melting points of the used constituent elements. The Mo foil is used to wrap over the each sample sothat there is no electrical connection between the samples during the process of annealing. The prepared samples have closed securely in the airtight quartz tube. For removal of impurities like oxygen and carbon traces, samples were annealed at a temperature of $850^{\circ} \mathrm{C}$ for 48 hours. The other benefit of high temperature annealing helps to form best quality samples because of homogeneous mixture of constituent elements. It has been noticed that annealing also helps in the growth of the grain size of the sample. On the expansion of the grains in the samples, the bulk impurities present in the inter-grain space like oxygen and carbon come out to the surface.

\section{RESULTS AND DISCUSSION}

The X-ray photoelectron spectrum recorded on $\mathrm{Cu}_{0.9} \mathrm{Ni}_{0.1}$ alloy using monochromatic $\mathrm{AlK}_{\alpha}$ radiation is demonstrated in figure 1. The different electronic states of $\mathrm{Cu}$ and $\mathrm{Ni}$ are shown by all the sharp peaks. The features of $\mathrm{C} 1 \mathrm{~s}$ and $\mathrm{O} 1 \mathrm{~s}$ corresponding to common impurities like carbon and oxygen were found to be below detection limit of the spectrometer i.e.

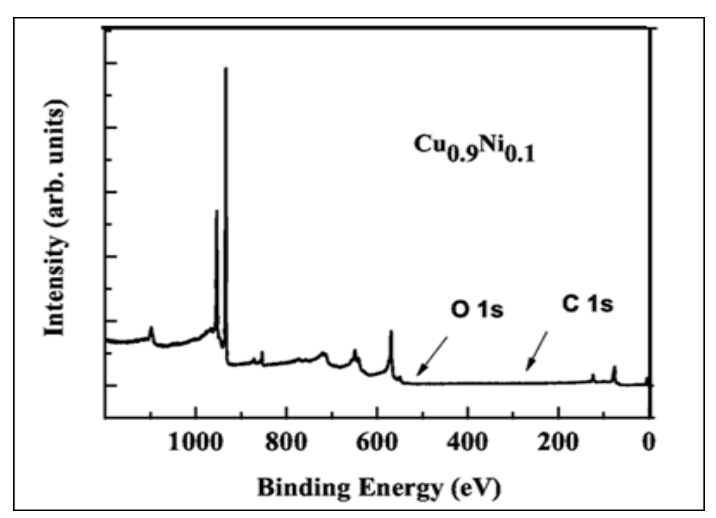

Fig 1. XPS spectrum of $\mathrm{Cu}_{0.9} \mathrm{Ni}_{0.1}$ alloy

below $0.1 \%$ in concentration. Similarly X-ray photoelectron spectra were also observed for other compositions indicating formation of good quality of the alloys. Fig. 2 shows the X-ray diffraction patterns of substitutionally random disordered $\mathrm{Cu}_{1-\mathrm{x}} \mathrm{Ni}_{\mathrm{x}}(\mathrm{x}=$ $0.1,0.3,0.5,0.7,0.9)$ alloys. The lattice parameters of the random disordered alloys were refined using POWDERX software [28]. The highest intensity reflection (111) occurs at around $44.3^{\circ}$ and exhibits slight variation in position with compositions. All the peaks are indexed assuming FCC structure for $\mathrm{CuNi}$ alloys. No impurity phases are observed, which again supports good quality of the preparation of random disordered alloys. The linear dependence of lattice parameters on composition of alloys [29] confirms the preparation of random disordered $\mathrm{CuNi}$ alloys as suggested by Vegard's law [30-31]. The lattice parameters and volume of the unit cell of the random disordered CuNi system have been calculated using Unit-Cell-Win software which is presented in Table 1 .

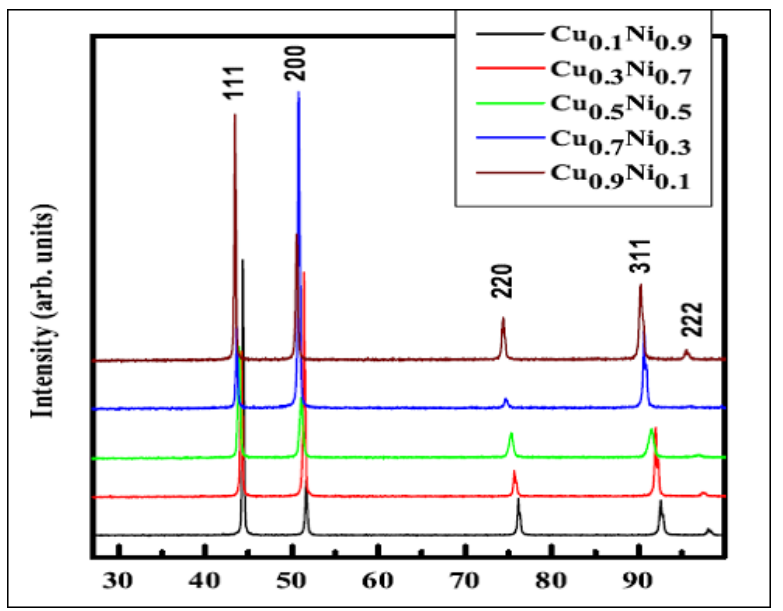

Fig 2. XRD patterns of $\mathrm{Cu}_{1-\mathrm{x}} \mathrm{Ni}_{\mathrm{x}}$ alloys recorded using $\mathrm{CuKa}$ radiation.

\section{Scherrer method:}

It is used to calculate crystalline size from the X-ray diffraction pattern of random disordered $\mathrm{CuNi}$ alloys. The Scherrer's equation can be written as, $D=\frac{\mathrm{k} \lambda}{\beta \cos \theta}$, where $\mathrm{D}$ $=$ crystallite size, $\lambda=$ wavelength of the used X-ray source $(\lambda$ $=1.54056 \AA), \mathrm{k}=$ anisotropic constant $(\sim 0.89), \theta=$ peak position and $\beta=$ full width at half maximum (FWHM) measured in radians [32]. The lattice strain, dislocations and defects of random alloys depend on the peak broadening $(\beta)$ [33]. On the simplification of Scherrer equation, we can write the expression in form of equation of straight line as,

$$
\mathrm{D}=\frac{\mathrm{k} \lambda}{\beta \cos \theta} \Rightarrow \cos \theta=\left(\frac{\mathrm{k} \lambda}{\mathrm{D}}\right) \frac{1}{\beta} \text {. }
$$

For a given composition of random alloy, select few reflections and plot $\frac{1}{\beta}$ as a function of $\cos \theta$ and fit a linear regression line. The slope of the linear regression line is equal to $\frac{\mathrm{k} \lambda}{\mathrm{D}}$. As $\mathrm{k}$ and $\lambda$ are given, crystallite size (D) can

be calculated. $\frac{1}{\beta}$ versus $\cos \theta$ for different compositions of $\mathrm{Cu}_{1-\mathrm{x}} \mathrm{Ni}_{\mathrm{x}}$ alloys are shown in fig. 3. For example in $\mathrm{Cu}_{0.9} \mathrm{Ni}_{0.1}$ alloy, the equation of the fitted line $\mathrm{y}(=$ $\cos \theta=0.56726+0.00166 \quad \mathrm{x}=1 \beta$ and $\mathrm{k} \lambda \mathrm{D}=0.00166$. Therefore, the calculated value of $\mathrm{D}$ is 79.59 . 

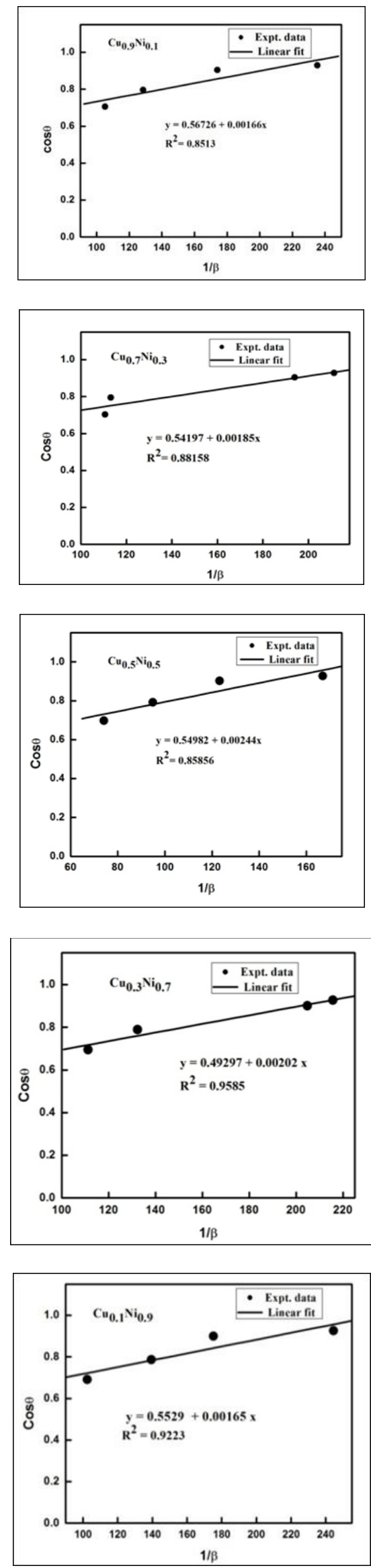

Fig 3. Scherrer plots $\mathrm{Cu}_{1-\mathrm{x}} \mathrm{Ni}_{\mathrm{x}}(\mathrm{x}=01,0.3,0.5,0.7,0.9)$ alloys. Fit to the data, the crystalline size $D$ is extracted from the slope of the fit line.

\section{Williamson-Hall Method:}

In this present study, during the preparation of random disordered alloys, the concentration of $\mathrm{Ni}$ atoms slowly increases and enters into the $\mathrm{Cu}$ vicinity. On account of changing of bond length, binding energy and local environment of $\mathrm{Cu}$ and $\mathrm{Ni}$ atoms in the random disordered $\mathrm{CuNi}$ alloys, the mechanical strain produced. A mathematical model has formulated by Williamson-Hall as $\beta \cos \theta=\frac{k \lambda}{D}+4 \varepsilon \sin \theta$, where $\varepsilon$ is the strain that produced in alloys. Two terms crystallite size and lattice strain are real contributors to the broadening of Bragg's peak observed in XRD analysis and in crystal imperfections and distortions in the material. The induced strain is given by Williamson-Hall (W-H) equation, $\varepsilon \approx \beta / \tan \theta$. This implies that the peak width $\beta$ has another contribution proportional to $\tan \theta$ coming from W-H equation apart from the contribution $\frac{1}{\cos \theta}$ given by the Scherrer equation. The total peak broadening that induced in random disordered alloys is an additive property. In designing the model, Williamson-Hall assumed that total broadening observed in Bragg's peak is equal to broadenings due to the crystallite size plus the broadening due to lattice strain [34]. The dependency of $\theta$ on the crystallite size and lattice strain is well defined in the W-H method [35]. The lattice strain is assumed to be uniform in all crystallographic directions is the basic of a mathematical model called Uniform Deformation model (UDM). In this model; a plot has to be drawn in which the term $4 \sin \theta$ is taken in $\mathrm{x}$-axis of the coordinate and $\beta \cos \theta$ is taken in $\mathrm{y}$ axis of coordinate. The slope of the fitted linear regression line gives lattice strain whereas y-intercept of the fitted linear regression line gives crystallite size shown in fig. 4. The crystallite size of the random disordered $\mathrm{Cu}_{1-\mathrm{x}} \mathrm{Ni}_{\mathrm{x}}(\mathrm{x}=$ $0.1,0.3,0.5,0.7,0.9)$ alloys has been calculated by both Scherrer and Williamson-Hall methods. Table 2 describes the resemblances with the crystallite sizes obtained by above two methods and also shows the strain calculated by W-H method. The average crystallite size estimated through Scherrer method and W-H method are reasonably in good agreement with a maximum deviation of $10 \mathrm{~nm}$ for $\mathrm{Cu}_{0.1} \mathrm{Ni}_{0.9}$ alloy. The agreement seems to be better for intermediate compositions $(x=0.3,0.5)$ as compared to others. The calculated strain increases gradually with $\mathrm{Ni}$ composition and becomes maximum for $\mathrm{Cu}_{0.5} \mathrm{Ni}_{0.5}$ alloy and then decreases for higher $\mathrm{Ni}$ concentrations. The $\mathrm{Cu}_{0.5} \mathrm{Ni}_{0.5}$ alloys possess maximum chemical disorder suggesting maximum in homogeneity at microscopic level. The strain in the lattice is proportional to the disorder in the alloy [36]. As the disorder increases with $\mathrm{Ni}$ concentration and exhibits a maximum at $x=0.5$, the same behavior is expected for the strain [37]. Interestingly W-H calculation exactly gives the same result as expected for disordered alloys. 

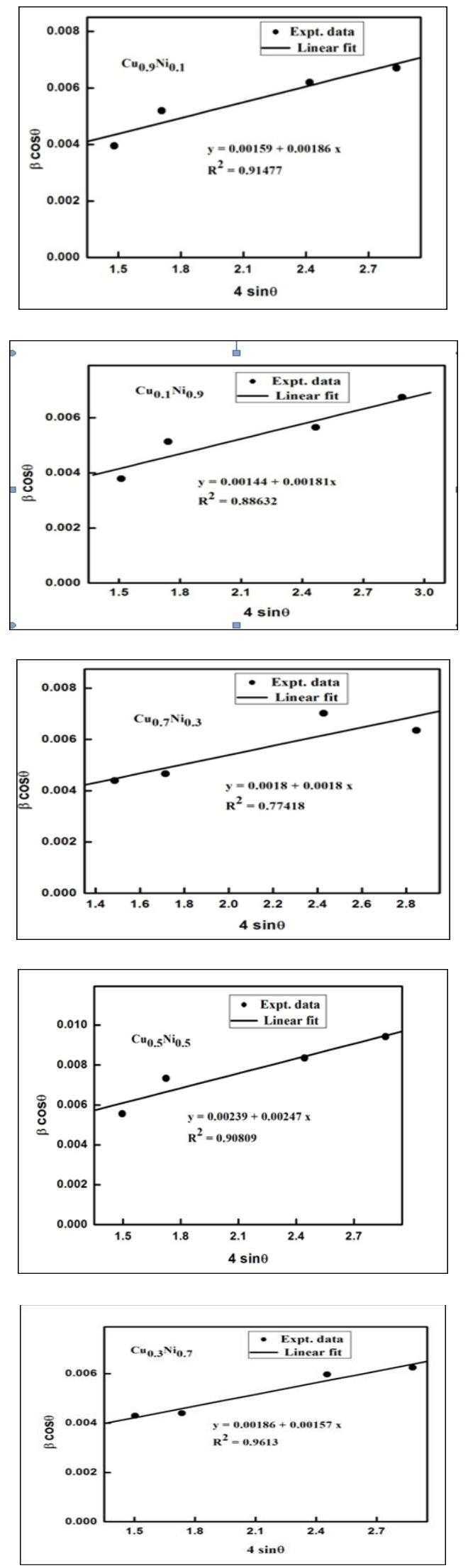

Fig 4. The Williamson-Hall analysis of $\mathrm{Cu}_{1-\mathrm{x}} \mathrm{Ni}_{\mathrm{x}}(\mathrm{x}=$ $0.1,0.3,0.5,0.7$ and 0.9 ) alloys assuming Uniform Deformation Model (UDM). Fit to the data, the strain is extracted from the slope and crystalline size $D$ is extracted from the $y$-intercept of the fit.
Table: 1 Lattice parameters and volume of

\begin{tabular}{|c|c|c|}
\hline \multicolumn{3}{|c|}{$C u_{1-x} N i_{x}(x=0.1,0.3,0.5,0.7,0.9)$ alloys [24] } \\
\hline Sample & $\begin{array}{c}\text { Lattice } \\
\text { parameter }(\AA)\end{array}$ & Volume $(\AA)^{3}$ \\
\hline $\mathrm{Cu}$ & $\mathrm{a}=3.61$ & 47.25 \\
\hline $\mathrm{Cu}_{0.9} \mathrm{Ni}_{0.1}$ & $\mathrm{a}=3.58$ & 45.88 \\
\hline $\mathrm{Cu}_{0.7} \mathrm{Ni}_{0.3}$ & $a=3.57$ & 45.49 \\
\hline $\mathrm{Cu}_{0.5} \mathrm{Ni}_{0.5}$ & $a=3.59$ & 46.26 \\
\hline $\mathrm{Cu}_{0.3} \mathrm{Ni}_{0.7}$ & $a=3.54$ & 44.36 \\
\hline $\mathrm{Cu}_{0.1} \mathrm{Ni}_{0.9}$ & $\mathrm{a}=3.51$ & 43.24 \\
\hline $\mathrm{Ni}$ & $a=3.52$ & 43.61 \\
\hline
\end{tabular}

Table: 2 Crystallite size and strain by Scherrer and Williamson-Hall methods

\begin{tabular}{|c|c|c|c|}
\hline Sample & $\begin{array}{c}\text { Scherrer } \\
\text { method }\end{array}$ & \multicolumn{2}{|c|}{$\begin{array}{c}\text { Williamson-Hall } \\
\text { method }\end{array}$} \\
\cline { 2 - 4 } & $\begin{array}{c}\text { Crystallit } \\
\text { e size } \\
(D) \text { in } \\
n m\end{array}$ & $\begin{array}{c}\text { Cryst } \\
\text { allite } \\
\text { size } \\
(D) \text { in } \\
n m\end{array}$ & Strain $(\varepsilon)$ \\
\hline $\mathrm{Cu}_{0.9} \mathrm{Ni}_{0.1}$ & 79.59 & 73.71 & 0.00159 \\
\hline $\mathrm{Cu}_{0.7} \mathrm{Ni}_{0.3}$ & 74.11 & 76.17 & 0.00180 \\
\hline $\mathrm{Cu}_{0.5} \mathrm{Ni}_{0.5}$ & 56.19 & 57.36 & 0.00247 \\
\hline $\mathrm{Cu}_{0.3} \mathrm{Ni}_{0.7}$ & 67.87 & 73.71 & 0.00157 \\
\hline $\mathrm{Cu}_{0.1} \mathrm{Ni}_{0.9}$ & 83.09 & 95.21 & 0.00181 \\
\hline
\end{tabular}

\section{CONCLUSION}

Different compositions of substitutionally random disordered $\mathrm{Cu}_{1-\mathrm{x}} \mathrm{Ni}_{\mathrm{x}}(0.1,0.3,0.5,0.7,0.9)$ alloys have been prepared by using arc-melting method. The XRD analysis confirms the formation of good quality single phase random disordered CuNi alloys which is well supported from XPS spectrum. The both Scherrer and Williamson-Hall method are employed to evaluate the average crystallite size of random disordered $\mathrm{Cu}_{1-\mathrm{x}} \mathrm{Ni}_{\mathrm{x}}(\mathrm{x}=$ $0.1,0.3,0.5,0.7,0.9$ alloys and the result is well matched. Williamson-Hall method was used to analyze the individual contribution of crystallite sizes and lattice strain on the Bragg's peak broadening of the $\mathrm{Cu}_{1-\mathrm{x}} \mathrm{Ni}_{\mathrm{x}}(\mathrm{x}=$ $0.1,0.3,0.5,0.7,0.9$ alloys. The strain increases with increase in concentration of $\mathrm{Ni}$ and exhibits a maximum at $50 \% \mathrm{Ni}$ concentration.

\section{ACKNOWLEDGMENT}

Authors are thankful to UGC-DAE CSR, Indore, India for providing XRD data on the alloys and to Prof. K. Maiti, TIFR, Mumbai, India for providing XPS data.

\section{REFERENCES}

1. Zunger A and Mahajan S, Handbook on Semiconductors (Elsevier, Amsterdam, 2nd edition). 1994, 3, pp. 1399.

2. Chen A B and Sher A, Semiconductor Alloys: Physics and Materials Engineering. (Plenum Press, New York). 1995 
3. Pfeiler W, Alloy Physics: A Comprehensive Reference. (Wiley-VCH, Weinheim). 2007, pp. 1003.

4. Mikkelsen J C and Boyce J B, Atomic-Scale Structure of Random Solid Solutions: Extended X-Ray-Absorption Fine-Structure Study of Ga1-xInxAs. Phys. Rev. Lett. 1982 Nov., 49(19), pp. 1412-1415.

5. Thomas D G, Hopfield J J, and Frosch C J, Isoelectronic Traps Due to Nitrogen in Gallium Phosphide, Phys. Rev. Lett. 1965 November, 15(22), pp. 857-860.

6. Lai S and Klein M V, Evidence for Exciton Localization by Alloy Fluctuations in Indirect-Gap Ga As1-xPx. Phys. Rev. Lett. 1980 April, 44 (16), pp. 1087-1090.

7. Permogorov S, Reznitsky A, Travnikov V, Verbin S, Resonant secondary emission of localized excitons in CdSI-xSex mixed crystals. J. Luminescence. 1981 November, 24-25(1), pp. 409-412.

8. Siegbahn K, Electron Spectroscopy for atoms, molecules and condensed matter. Rev. Mod. Physics. 1982 July, 54 (3), pp. 709-728.

9. Norris C and Myers H P, Photoemission study of the electronic structure of silver palladium alloys. J. Phys. F: Metal Phys. 1971 January, 1(1), pp. 62-77.

10. McLachlan A D, Jenkin J G, Leckey R C G and Liesegang J, A valence band study of Ag-Pd alloys using ultraviolet photoelectron spectroscopy. J. Phys. F: Metal Phys. 1975 December, 5 (12), pp. 2415-2424.

11. Berndt K, Marx U and Brummer O, Photoelectron spectra of core electrons from palladium-silver alloys, Phys. Stat. Sol. B. 1979 August, 94 (2), pp. 541-548.

12. Prince $\mathrm{K} \mathrm{C}$ and $\mathrm{Chab} \mathrm{V}$, Electronic structure of $\mathrm{Pd} / \mathrm{Ag}$ surface alloys. J. Electron Spec. and Relat. Phen. 1990, 52, pp. 61-66.

13. Parida S K, Medicherla V R R, Bag P, Rawat R, Shripathi T, Sahadev N, Biswas D, Adhikary G and Maiti $\mathrm{K}$, Virtual bound state formation in CuNi alloys. Adv. Sci. Lett. 2014 March/April, 20 (3/4), pp. 758-760.

14. Parida S K, Medicherla V R R, Bag P, Rawat R, Shripathi T, Sahadev N, Biswas D, Adhikary G and Maiti $\mathrm{K}$, Local environment effect on Ag M4,5VV Auger spectra of Ag1-xPdx alloys. Adv. Sci. Lett. 2014 March/April, 20 (3/4), pp. 792-794.

15. Miyahara $\mathrm{T}$ et. al, Resonant photoemission study on valence band satellites of CuxNi1- $\mathrm{x}$ and AgxPd1-x alloy systems. J. Phys. Soc. of Japan. 1989 June, 58 (6), pp. 2160-2166.

16. Lu Z W, Wei S H and Zunger A, Electronic structure of random Ag0.5 Pd0.5 and Ag0.5Au0.5 alloys. Phys. Rev. B. 1991 November, 44 (19), pp. 10470-10484

17. Oh S J and Nahm T Uh, Electronic structures of noble metal-Pd binary alloys studies by photoemission using synchrotron radiation. J. Elec. Spec. and Relat. Phen. 1996 May, 78, pp. 43-48.

18. Kleiman G G, Landers R, de Castro S D C and Nascente P A P, Core-level Auger energy shifts in palladium alloys. Surface Science. 1993 May, 287/288 (part 2), pp. 794-797.

19. Kokko $\mathrm{K}$ et.al, From X-ray absorption near edge structure of the d-hole population in Pd-Ag alloys. Phys. Rev. B. Condensed Matter. 1999 August, 60 (7), pp. 4659-4664.

20. Santra A K and Rao C N R, Surface alloy formation in $\mathrm{Pd} / \mathrm{Ag}, \mathrm{Cu} / \mathrm{Au}$ and $\mathrm{Ni} / \mathrm{Au}$ bimetallic overlayers. Applied Surface Science. 1995 April, 84 (4),1995, pp. 347-350.

21. Coulthard I and Sham T K, Charge redistribution in PdAg Alloys from local perspective. Phys. Rev. Lett. 1996 December, 77 (23), pp. 4824-4827.

22. Faulkner J S, Wang Y, and Stocks G M, Core level chemical shifts in metallic Alloys. Phys. Rev. Lett. 1998 August, 81(9), pp. 1905-1908.

23. Olovsson W, Abrikosov I A and Johansson B, Core level shift in random $\mathrm{CuPd}$ and $\mathrm{AgPd}$ alloys by complete screening picture. J. Elect. Spec. and Relat. Phen. 2002 November, 127 (1-2), pp- 65-69.

24. Lubarda V A, On the effective lattice parameter of binary alloys. Mechanics of Materials. 2003 January-February, 35 (1-2), pp-53-68.

25. Mouffok B, Feraoun $\mathrm{H}$ and Aourag H, Vacancy effect in CuAg alloys. Material Letters. 2006 May, 60 (11), pp1344-1346.

26. Chang L L, Wen S, Li S L, Zhu X D, and Shang X J, Strain softening during tension in cold drawn $\mathrm{Cu}-\mathrm{Ag}$ alloys. Materials Characterization. 2015 October, 108, pp-145-151.

27. Tian Y Z, Li J J, Zharg P, Wu S D, Zhang Z F, Kwasaki $\mathrm{M}$, and Langdon $\mathrm{T} \mathrm{G}$, Microstructures, strengthening mechanisms and fracture behavior of $\mathrm{Cu}-\mathrm{Ag}$ alloys processed by high-pressure torsion. Acta Materialia. 2012 January, 60 (1), pp-269-281.

28. C Dong, PowderX: Powder Diffraction Analysis Software (beta version), Institute of Physics, Chinese Academy of Sciences, P.O. Box 603, Beijing 100080, P.R. China. E-mail: chengdon@aphy.iphy.ac.cn, Web Page: http://www.ccp14.ac.uk/tutorial/powderx/

29. VRR Medicherla, S K Parida, P Bag, R Rawat, T. Shripathi et al., Core level spectra of disordered $\mathrm{Cu}-\mathrm{Ni}$ alloys. AIP Conf. Proc., 1461, 2012, pp-275-278.

30. A B M Almamum Ashrafi and Y Segawa, Determination of $\mathrm{Mg}$ composition in MgxZ1-xO alloy: Validity of Vegard's Law. J. Vac. Sci. Technol. B, 23, 2005 , pp2030-2033.

31. K T Jacob, S Raj, L Rannesh, Vegard's law: a fundamental relation or an approximation? International Journal of Materials Research, 98, 2007, pp-776-779.

32. K P Gupta, The Cu-Ni-Y (Copper-Nickel-Yttrium) System. Journal of Phase Equilibria and Diffusion, 30, 2009, pp- 651-656.

33. B D Cullity and S R Stock, Elements of X-ray Diffraction. (3rd edition, Upper Saddle River, NJ: Prentice Hall), ISBN: 9780201610918, 1-664 (2001)

34. K D Rogers and P Daniels, An X-ray diffraction study of the effects of heat treatment on bone mineral microstructure. Biomaterials, 23, 2002, pp-2577-2585.

35. A K Zak, W H Abd Majid, M E Abrishami, R Yousefi, $\mathrm{X}$-ray analysis of $\mathrm{ZnO}$ nanoparticles by Williamson-Hall and size-strain plot methods. Solid State Sciences, 13(1), 2011, pp-254-256.

36. V.A. Lubarda, On the effective lattice parameter of binary alloys, Mechanics of Materials, 35,2003, pp- 5368.

37. P.G. Klemens, The Lattice Component of the Thermal Conductivity of Metals and Alloys, Australian Journal of Physics, vol. 7, 1953, pp-57-63.

\section{AUTHORS PROFILE}

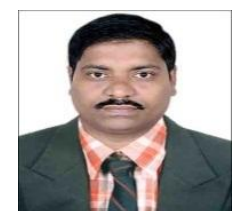

First Author Dr. Santosh Kumar Parida currently is working as Assistant Professor in the Faculty of Engineering \& Technology ITER, Siksha ' $\mathrm{O}$ ' Anusandhan deemed to be University. My current research includes Material Science, Polymer Composites, Metallic alloys, and Multiferroic materials. I have published 14 international journal papers and guiding two research scholars. 


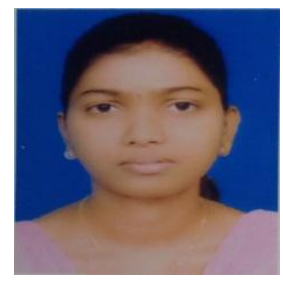

Second Author Mrs. Maheswari Mohanta, research scholar of the department of Physics, ITER, Siksha 'O' Anusandhan deemed to be University. I have two years of teaching and research experience.

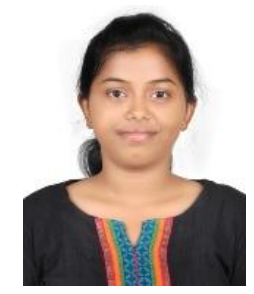

Third Author Mrs. Ananya Sahoo, research scholar of the department of Physics, ITER, Siksha 'O' Anusandhan deemed to be University. I have two years of teaching and research experience.

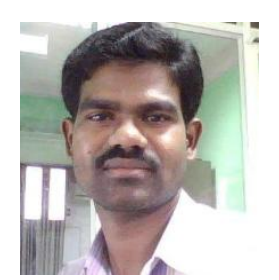

Four Author Rajendra Meher currently is working as Assistant Professor in ${ }^{2}$ Department of Medical Physics, Acharya Harihar Regional Cancer Centre, Cuttack, Odisha. I have 10 years of teaching experience and two years research experience.

Five Author Prof. (Dr.) V. R. Rao Medicherla currently is working as Professor in the Faculty of Engineering \& Technology ITER, Siksha 'O' Anusandhan deemed to be University. My current research includes transition metallic alloys and magnetism. I have more than 25 years of teaching and research experience. 